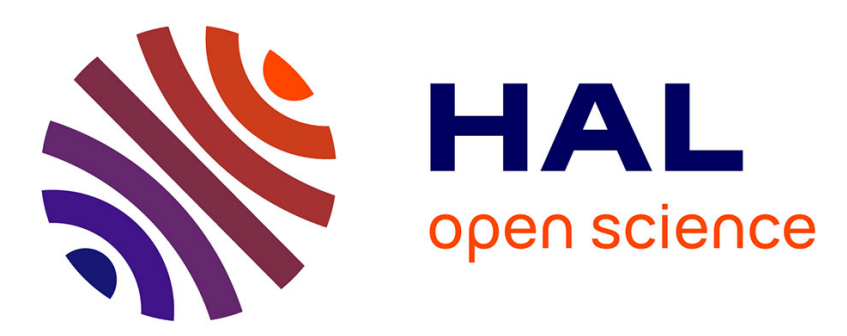

\title{
Advanced Pd/CexZr(1-x)O2/MCM-41 catalysts for methane combustion: Effect of the zirconium and cerium loadings
}

Imen Ben Saïd, Khouloud Sadouki, Sylvie Masse, Thibaud Coradin, Leila Samia Smiri, Shemseddine Fessi

\section{To cite this version:}

Imen Ben Saïd, Khouloud Sadouki, Sylvie Masse, Thibaud Coradin, Leila Samia Smiri, et al.. Advanced $\mathrm{Pd} / \mathrm{CexZr}(1-\mathrm{x}) \mathrm{O} 2 / \mathrm{MCM}-41$ catalysts for methane combustion: Effect of the zirconium and cerium loadings. Microporous and Mesoporous Materials, 2018, 260, pp.93-101. 10.1016/j.micromeso.2016.10.044 . hal-01504587

\section{HAL Id: hal-01504587 \\ https://hal.sorbonne-universite.fr/hal-01504587}

Submitted on 11 Apr 2017

HAL is a multi-disciplinary open access archive for the deposit and dissemination of scientific research documents, whether they are published or not. The documents may come from teaching and research institutions in France or abroad, or from public or private research centers.
L'archive ouverte pluridisciplinaire HAL, est destinée au dépôt et à la diffusion de documents scientifiques de niveau recherche, publiés ou non, émanant des établissements d'enseignement et de recherche français ou étrangers, des laboratoires publics ou privés. 


\title{
Advanced $\mathrm{Pd} / \mathrm{Ce}_{\mathrm{x}} \mathrm{Zr}_{(1-\mathrm{x})} \mathrm{O}_{2} / \mathrm{MCM}-41$ catalysts for methane combustion: Effect of the zirconium and cerium loadings
}

\author{
Imen Ben Saïd ${ }^{2}$, Khouloud Sadouki ${ }^{3}$, Sylvie Masse ${ }^{4}$, Thibaud Coradin ${ }^{4}$, Leila Samia \\ Smiri ${ }^{2}$, Shemseddine Fessi ${ }^{1}$ \\ ${ }^{1}$ University of Jeddah, Faculty of Science and Arts-Khulais, Chemistry Department, Jeddah, Kingdom of Saudi \\ Arabia, shemseddinefessi@yahoo.fr. \\ ${ }^{2}$ Unité de Synthèse et Structure de Nanoparticules, Département de Chimie, Faculté des Sciences de Bizerte, \\ Université de Carthage-Tunis, Tunisie, imenbensaid32@yahoo.fr, 1smiri@gmail.com. \\ ${ }^{3}$ Laboratoire de Chimie des Matériaux et Catalyse, Département de Chimie, Faculté des Sciences de Tunis, \\ Université Tunis-El Manar, Campus Universitaire 2092 Tunis, Tunisie, kouloudsadouki@yahoo.fr. \\ ${ }^{4}$ Sorbonne Universités, UPMC Univ Paris 06, CNRS, Collège de France, Laboratoire de Chimie de la \\ Matière Condensée de Paris, 11 place Marcelin Berthelot, 75005 Paris, France, \\ sylvie.masse@upmc.fr, thibaud.coradin@upmc.fr.
}

\begin{abstract}
$\mathrm{Pd} /\left(\mathrm{Ce}_{\mathrm{x}} \mathrm{Zr}_{(1-\mathrm{-x})} \mathrm{O}_{2}\right) / \mathrm{MCM}-41$ catalysts containing variable loadings of $\mathrm{Ce}$ and $\mathrm{Zr}$ with fixed molar ratio $\mathrm{Ce} / \mathrm{Zr}=1 / 2$ are prepared by impregnation. Synthesized $\mathrm{MCM}-41, \mathrm{Pd}(\mathrm{acac})_{2}$, $\mathrm{Ce}\left(\mathrm{NO}_{3}\right)_{3} \cdot 6 \mathrm{H}_{2} \mathrm{O}$ and $\mathrm{Zr}(\mathrm{acac})_{4}$ are used as chemicals. The effect of $\mathrm{Ce}$ and $\mathrm{Zr}$ contents on the textural, structural and catalytic properties of the prepared catalyst is studied. $\mathrm{N}_{2^{-}}$ physisorption, $\mathrm{H}_{2}$-chimisorption, $\mathrm{XRD}$, TEM-EDX and TPR are the main techniques used to characterize these catalysts. The obtained results show that $\mathrm{Ce}$ and $\mathrm{Zr}$ addition impacts differently the surface area, porosity and particle sizes of the $\mathrm{Pd} /\left(\mathrm{Ce}_{\mathrm{x}} \mathrm{Zr}_{(1-\mathrm{x})} \mathrm{O}_{2}\right) / \mathrm{MCM}-41$ catalysts, depending on the variable amount of $\mathrm{Ce}$ and $\mathrm{Zr}$. A huge enhancement in the methane combustion activity is obtained.
\end{abstract}

Keywords: $\mathrm{Pd} /\left(\mathrm{Ce}_{\mathrm{x}} \mathrm{Zr}_{(1-\mathrm{x})} \mathrm{O}_{2}\right) / \mathrm{MCM}-41$ catalysts; Methane combustion; Catalytic activity

\section{Introduction}

Natural gas provides an attractive source of energy since it is an abundant supply. It has found an application in the turbine combustion chambers and more recently has been reported as an alternative fuel for automotive applications [1-2]. In these fields, the catalytic combustion has proven to be a suitable alternative to the conventional flame combustion. Actually, the catalytic process reduces considerably the noxious emissions of nitrogen oxides NOx, and unburned hydrocarbons [3]. Palladium-based catalysts are often seen as the clear 
choice for the catalytic combustion process due to its high activity $[4,5]$. Nevertheless, the catalyst deactivation due to palladium sintering during heat treatments is the most serious problem for this kind of catalysts [6]. Therefore, it is necessary to modify the Pd-based catalysts in order to improve their thermal stability. The support and the additives are some of the parameters that may affect the catalyst thermal stability and consequently its activity. According to the literature [1, 7-9], the introduction of some rare-earth oxides such as Ce, La, $\mathrm{Tb}, \mathrm{Pr}, \mathrm{Nd}$ and $\mathrm{Y}$ can improve the sintering resistance. Among these dopants, cerium oxide is widely reported to be an excellent promoter for palladium-based catalysts due to its capacity to stabilize the metal dispersion, to improve the palladium reducibility and to enhance the oxygen storage $[8,9]$. However, with temperatures higher than $500^{\circ} \mathrm{C}, \mathrm{CeO}_{2}$ readily sinters resulting in catalyst deactivation. The addition of zirconium into the cubic $\mathrm{CeO}_{2}$ framework is seen to be an effective method to increase thermal stability and to improve oxygen mobility resulting in better performance in catalytic methane combustion $[9,10]$.

Furthermore, it is well known that the nature of the metal-support interaction may strongly influence the catalyst thermal stability. Actually, traditional supports such as $\mathrm{Al}_{2} \mathrm{O}_{3}$, $\mathrm{ZrO}_{2}$ and $\mathrm{SiO}_{2}$ show insufficient properties in terms of thermal stability and activity [11-14].

Recently developed mesoporous silicates, such as M41S and SBA-x families, have become popular materials for application as new catalyst supports due to their high specific surface area, to their well defined and ordered pore structure and to their reasonable thermal stability $[6,15]$. Also, it has been reported that silicates are adequate supports for methane combustion catalysts $[3,9,16,17]$. Nevertheless, there are no frequent investigations about ceria and zirconia addition to palladium based MCM-41 for the catalytic methane combustion.

This contribution aims to evaluate the performance in methane combustion of the $\mathrm{Pd} / \mathrm{MCM}-41$ catalysts doped with $\mathrm{Ce}$ and $\mathrm{Zr}$. In particular, attention is given to the effect of Ce and $\mathrm{Zr}$ contents on the textural, structural and catalytic properties of the doped Pd/MCM- 
41 catalysts. For these reasons, $\mathrm{Pd} /\left(\mathrm{Ce}_{\mathrm{x}} \mathrm{Zr}_{(1-\mathrm{x})} \mathrm{O}_{2}\right) / \mathrm{MCM}-41$ samples are prepared with $\mathrm{Zr}$ loadings of $0,5,10$ and 20 wt.\% and Ce contents to have Ce/ $\mathrm{Zr}$ molar ratio equal to $1 / 2$. Then, the catalysts are characterized by means of different techniques and tested in methane combustion.

\section{Experimental}

\subsection{Chemicals}

Hexadecyltrimethylammonium bromide, (CTAB) (Sigma-Aldrich, $\geq 99 \%$ ), ammonium hydroxide solution (Sigma-Aldrich, $\geq 99.99 \%$ ), tetraethyl orthosilicate, (TEOS) (ACROS, 98\%), ethanol, (EtOH) (Sigma-Aldrich, $\geq 99.8 \%$ ), cerium nitrate $\mathrm{Ce}\left(\mathrm{NO}_{3}\right)_{3} \cdot 6 \mathrm{H}_{2} \mathrm{O}$ (SigmaAldrich, 99.99\%), zirconium acetylacetonate, $\mathrm{Zr}$ (acac) 4 (Sigma-Aldrich, 99.99\%) and palladium acetylacetonate, $\left(\operatorname{Pd}(\mathrm{acac})_{2}\right)($ Sigma-Aldrich, 99\%) are used as chemicals in this work.

\subsection{MCM-41 preparation}

The MCM-41 synthesis is performed according to the reported procedure [18]. In brief: $1 \mathrm{~g}$ of CTAB is dissolved in $200 \mathrm{~mL}$ of deionized water. Aqueous ammonia (28 wt. \%) is then added until the $\mathrm{pH}$ of the solution is adjusted to 10.5 . Then, TEOS $(5 \mathrm{~mL})$ is added drop wise at $70^{\circ} \mathrm{C}$ for $1 \mathrm{~h}$. After, the mixture is let for cooling to room temperature under stirring for $12 \mathrm{~h}$. The obtained solid is then separated by centrifugation and washed with distilled water and ethanol. Finally, the solid is dried in an oven at $60^{\circ} \mathrm{C}$ for $1 \mathrm{~h}$ and then calcined at $550^{\circ} \mathrm{C}$ for $4 \mathrm{~h}$.

\subsection{Catalysts preparation}

The $\mathrm{Pd} /\left(\mathrm{Ce}_{\mathrm{x}} \mathrm{Zr}_{(1-\mathrm{x})} \mathrm{O}_{2}\right) / \mathrm{MCM}-41$ catalysts are prepared by impregnation. Appropriate amounts of $\mathrm{Pd}(\mathrm{acac})_{2}(\% \mathrm{Pd}=0.5$ wt.\%. $), \mathrm{Zr}(\mathrm{acac})_{4}, \mathrm{Ce}\left(\mathrm{NO}_{3}\right)_{3} \cdot 6 \mathrm{H}_{2} \mathrm{O}$ and calcined $\mathrm{MCM}-41$ are ground in an agate mortar for $10 \mathrm{~min}$. Then, methanol is added to obtain a paste which is 
dried in an oven at $60^{\circ} \mathrm{C}$ for 30 minutes. Finally, the obtained solid is calcined at $550{ }^{\circ} \mathrm{C}$. The resulting catalysts are referred as Pd-CeZrx, where $\mathrm{x}$ is the zirconium loading that varied from 0 to $20 \mathrm{wt} . \%$. The molar ratio $\mathrm{Ce} / \mathrm{Zr}$ is fixed to be equal to $1 / 2$.

\subsection{Characterization techniques}

The specific surface area is determined from $\mathrm{N}_{2}$ adsorption isotherms at $77 \mathrm{~K}$ with the BET method using a Belsorp Max analyzer. Prior to adsorption measurement, the sample is degassed at $150^{\circ} \mathrm{C}$ under vacuum. The pore size distribution is determined by the $\mathrm{BJH}$ method, using the desorption branches of isotherms. The total pore volume is estimated by means of the total amount of adsorbed gas at relative pressure $\mathrm{P} / \mathrm{P}_{0}=0.98$.

The crystalline phases of the various samples are determined by X-ray powder diffraction using a D8 ADVANCE Bruker apparatus operated at monochromatic $\mathrm{Cu} \mathrm{K} \alpha$ radiation, $30 \mathrm{~mA}$ and $40 \mathrm{kV}$. XRD patterns are recorded in the $2 \theta$ range of $10-80^{\circ}$.

The metallic particle sizes are analyzed by transmission electron microscopy (TEM) using a TECNAÏ Spirit 120 apparatus operated at a $120 \mathrm{kV}$ accelerating voltage and equipped with a GATAN numeric camera. Each sample is dispersed on a $3 \mathrm{~mm}$ carbon-coated copper grid by deposition of a drop of a diluted suspension containing the particles in ethanol, after sonication.

Temperature-programmed reduction (TPR) of the catalysts is carried out in a stream of 5 vol. $\% \mathrm{H}_{2}$ balanced with Ar at a flow rate of $30 \mathrm{~mL} / \mathrm{min}$. The sample is heated in a U-shaped conventional quartz micro reactor in oxygen with a flow rate of $30 \mathrm{~mL} / \mathrm{min}$ up to $500^{\circ} \mathrm{C}$ and kept at this temperature for $1 \mathrm{~h}$. After staying under Ar stream for $1 \mathrm{~h}$, the sample is finally cooled to room temperature. After, the stream is switched from Ar to the reducing gas the sample is heated to $350^{\circ} \mathrm{C}$ by increasing the temperature linearly at a constant rate of $10^{\circ} \mathrm{C} / \mathrm{min}$. The hydrogen consumption is monitored using a thermal conductivity detector. 
The catalytic activity test for methane combustion is carried out in a quartz fixed-bed micro-reactor at atmospheric pressure over the oxidized sample (100 $\mathrm{mg})$. The reaction mixture contains 1vol.\% $\mathrm{CH}_{4}, 4$ vol.\% $\mathrm{O}_{2}$ and balance He with a total flow rate of $6 \mathrm{~L} \mathrm{~h}^{-1}$. Reaction products are analyzed on-line by a gas chromatograph equipped with a thermal conductivity detector (TCD) and a Porapak column. The measurement of methane conversion is carried out from $300^{\circ} \mathrm{C}$ to $500^{\circ} \mathrm{C}$ and is determined as follows:

$$
\text { Conversion }(\%)=\frac{P(\mathrm{CO} 2)}{P(\mathrm{CH} 4)+P(\mathrm{CO} 2)} \times 100
$$

where $\mathrm{P}_{\mathrm{CH} 4}$ and $\mathrm{P}_{\mathrm{CO} 2}$ are respectively, the partial pressures of methane and carbon dioxide.

\section{Results and discussion}

\subsection{Textural characterization}

The $\mathrm{N}_{2}$ adsorption-desorption isotherms of all the Pd-CeZrx catalysts show profiles identical to the type IV (according to the IUPAC classification), characteristic of mesoporous solids (Fig. 1A). However, only the hysteresis loops of the Pd-CeZr0, the Pd-CeZr5 and the Pd-CeZr10 isotherms are identified as H1 type, characteristic of uniform cylindrical mesopores (according to the IUPAC classification). The hysteresis loop turns to the H3 type for the Pd-CeZr20 catalyst. In addition, as it is shown in Fig. 1B, the Pd-CeZr0 sample exhibits narrow and unimodal pore size distribution with an average pore diameter of $31 \AA$. However, the introduction of $\mathrm{Ce}$ and $\mathrm{Zr}$ turns the distribution to a tri-modal pore size distribution on the Pd-CeZr5 sample, with pore diameters at 27, 43 and $203 \AA$. Likewise, the further increase of $\mathrm{Ce}$ and $\mathrm{Zr}$ loadings on the Pd-CeZr10 and the Pd-CeZr20 catalysts shifts

the tri-modal distribution to pore diameters at 24,36 and $230 \AA$. In addition to this porosity modification, the BET surface area and the pore volume decreased greatly by the increase of the cerium and zirconium contents. These results can be explained by the appearance of new types of pores due to the destruction of the internal walls of some mesopores when $\mathrm{Ce}$ and $\mathrm{Zr}$ loadings are increased. In effect, the textural modifications occur first by the coverage of the 
pore walls with layers of metallic particles in the internal channels, then a blockage of some pores happens by the further deposition of ceria and zirconia nanoparticles and finally a destruction of the internal pore walls occurs due to excessive insertion of Ce and Zr. Similar phenomenon has been observed in the literature [19].

\subsection{Palladium dispersion}

Measurement of palladium dispersion is accomplished by $\mathrm{H}_{2}$ chemisorption. The obtained results gathered in Table 1, show that palladium dispersion of the prepared catalysts increases in the following order: $\mathrm{Pd}-\mathrm{CeZr} 0<\mathrm{Pd}-\mathrm{CeZr} 5<\mathrm{Pd}-\mathrm{CeZr} 10 \approx \mathrm{Pd}-\mathrm{CeZr} 20$. These results suggest that $\mathrm{Ce}$ and $\mathrm{Zr}$ addition enhances significantly the palladium dispersion probably due to the sintering inhibition of the $\mathrm{PdO}$ particles. This thermal stability improvement could be favored by the strengthening of the PdO-support interaction. Z. Z. Liang et al. [20] have also studied the $\mathrm{Pd} /\left(\mathrm{Ce}_{\mathrm{x}} \mathrm{Zr}_{1-\mathrm{x}} \mathrm{O}_{2}\right) / \mathrm{SiO}_{2}$ catalysts and they have shown that the increase in $\mathrm{Zr}$ loading enhances the metallic dispersion.

\subsection{XRD measurements}

The XRD patterns of the all catalysts are shown in Fig. 2. Those of the Pd-CeZr0 sample reveals the presence of the characteristic peak of tetragonal PdO phase around $2 \theta=$ 32.5 $5^{\circ}$ Compared to the diffraction patterns of the $\mathrm{Pd} / \mathrm{CeO}_{2} / \mathrm{MCM}-41$ sample (Fig. 2B), positioned at $2 \theta=28.5,47.5$ and $56.3^{\circ}$, and attributed to the ceria cubic phase [21]. The PdCeZr10 and the Pd-CeZr20 catalysts show the same patterns as $\mathrm{Pd} / \mathrm{CeO}_{2} / \mathrm{MCM}-41$ catalyst but peaks are broader and shifted to higher $2 \theta$ positions $\left(2 \theta=29.5^{\circ}, 48.4^{\circ}\right.$ and $\left.57.3^{\circ}\right)$. This shift indicates the substitution of $\mathrm{Ce}^{4+}$ ions by $\mathrm{Zr}^{4+}$ ions in the ceria lattice to form $\mathrm{Ce}_{\mathrm{x}} \mathrm{Zr}_{1-\mathrm{x}} \mathrm{O}_{2}$ solid solution. These results are in agreement with those described in the literature which indicates that greater is the $\mathrm{Zr}$ loading, larger is the shift of the solid solution peaks [21, 22]. Based on these observations and on the fact that no diffraction peaks of zirconia phases are 
detected, it can be concluded that a part of the $\mathrm{Zr}$ amount is incorporated into the $\mathrm{CeO}_{2}$ phase and the rest remains well dispersed.

Moreover, we can see that peaks of Pd-CeZr10 are broader than those of the Pd$\mathrm{CeZr} 20$ which indicates that $\mathrm{Ce}$ and $\mathrm{Zr}$ particle sizes increase with their loadings. Furthermore, in addition to the peak around $2 \theta=32.5^{\circ}$, no XRD diffractions are related to $\mathrm{CeO}_{2}, \mathrm{ZrO}_{2}$ or $\mathrm{CeZrO}_{2}$ are observed on the patterns of the Pd-CeZr5 catalyst. This indicates that no crystalline phase of the mixed oxides is agglomerated on the surface of the MCM-41 support. Such result may be comprehensible since the loadings of zirconium and cerium are relatively low.

\subsection{TEM characterization}

The size of the metallic particles on the Pd-CeZrx catalysts is examined by TEM characterization. Micrographs of the Pd-CeZr0 catalyst (Fig. 3a) show a good dispersion state and homogeneous distribution of the Pd particle size. Pd is well detected in the EDXA signals collected from different local areas of the catalyst surface (Fig. 3b). According to the particle size distribution (Fig. 3c), the average Pd particle size is about $6 \pm 2 \mathrm{~nm}$.

For the Pd-CeZr5 micrographs (Fig. 3d), the metallic particles are well dispersed on the surface of the support. The average particle size is about $4 \pm 1 \mathrm{~nm}$ (Fig. 3e). However, we can also observe some aggregates like nanowires of about $40 \mathrm{~nm}$ of length which are attributed to some $\mathrm{PdO}$ particles. For the $\mathrm{Pd}-\mathrm{CeZr} 10$ and the $\mathrm{Pd}-\mathrm{CeZr} 20$ samples, we note the presence of relatively small particles on the support surface (Fig 3f, h). The crystallite sizes are smaller than $3 \mathrm{~nm}$. The EDXA analysis (Fig. $\mathbf{4 j}$ ), shows different signals, corresponding to Pd, Ce and Zr. This result suggests that metallic oxides are well dispersed. Moreover, from the HRTEM (Fig. 3g, i), it appears that the lattice spacing of nanoparticles are $0.263 \mathrm{~nm}$ and $0.291 \mathrm{~nm}$ which are respectively indexed as the (101) and (111) planes of tetragonal $\mathrm{PdO}$ and $\mathrm{Ce}_{\mathrm{x}} \mathrm{Zr}_{(1-}$ ${ }_{x)} \mathrm{O}_{2}$ solid solution [23]. Thus, it can be concluded from these results that the metallic particle 
size is significantly influenced by the Ce and $\mathrm{Zr}$ loadings. In fact, the $\mathrm{Zr}$ and Ce addition can improve the dispersion of the supported Pd particles.

\subsection{Palladium reducibility}

The recorded $\mathrm{H}_{2}$-TPR profiles of the Pd-CeZrx catalyst are shown in Fig.4. A negative peak at $33^{\circ} \mathrm{C}$ which is ascribed to the decomposition of the $\mathrm{PdH}_{\mathrm{x}}$ species is observed on the Pd-CeZr0 profile (Fig. 4a). Normally, this peak should follow a positive one caused by the reduction of $\mathrm{PdO}$. This reduction step seems to occur at negative temperature since it is not registered on the TPR profile. This result is in agreement with the literature $[24,25]$ which suggested that large $\mathrm{PdO}_{\mathrm{x}}$ species supported on $\mathrm{SiO}_{2}$ could be reduced at low temperatures. In addition, it was established [25] that Pd crystallites adsorb hydrogen to form $\mathrm{PdH}_{\mathrm{x}}$ species, which decompose by the temperature increase.

The introduction of $\mathrm{Zr}$ and $\mathrm{Ce}$ on the $\mathrm{Pd} / \mathrm{MCM}-41$ affects the $\mathrm{Pd}-\mathrm{CeZr0}$ reducibility. In fact, the TPR profile of the Pd-CeZr5 catalyst (Fig. 4b) shows the $\mathrm{PdH}_{\mathrm{x}}$ decomposition signal at around $61^{\circ} \mathrm{C}$. This shift shows that $\mathrm{PdO}$ species of the $\mathrm{Pd}-\mathrm{CeZrO}$ sample are more reducible than those of the Pd-CeZr5 catalyst [26].

The further increase of $\mathrm{Ce}$ and $\mathrm{Zr}$ loadings, leads the TPR profile of the Pd-CeZr10 sample to exhibit two positive peaks at $25^{\circ} \mathrm{C}$ and $105^{\circ} \mathrm{C}$, which could be attributed to the reduction of more stable PdO species in strong interactions with the support $[19,21,27]$. A similar peak appear at higher temperature (around $160^{\circ} \mathrm{C}$ ) on the TPR profile of the $\mathrm{Pd}-\mathrm{CeZr} 20$ sample (fig. 5d), probably due to additional interaction strength between Pd and the support. This hypothesis could be strengthened by the absence of the $\mathrm{PdH}_{\mathrm{x}}$ decomposition peak on the PdCeZr10 and the Pd-CeZr20 profiles. In effect, according to the literature [20, 28-30], the strong interaction of $\mathrm{Pd}$ to the $\mathrm{Ce}-\mathrm{Zr}$ oxides inhibits the formation of the $\mathrm{PdH}_{\mathrm{x}}$ species. Consequently, these results indicate that the increase of $\mathrm{Ce}$ and $\mathrm{Zr}$ content on the Pd-CeZrx catalysts enhances the $\mathrm{PdO}$ interaction with $\mathrm{Ce}$ and $\mathrm{Zr}$ oxides which increases their reduction 
temperatures and consequently lowers their reducibility. Similar results were reported by J.A.C. Ruiz et al. [9]. These authors suggested that the increase of cerium content on the $\mathrm{Pd} / \mathrm{CeO}_{2}$ catalyst increases the reduction temperature of $\mathrm{PdO}$, which reveals that less reducible species are present in this sample. Furthermore, these results are in agreement with TEM observations, since the catalysts with the lower metal particle sizes (higher $\mathrm{Ce}$ and $\mathrm{Zr}$ loadings) have the higher reduction temperature. According to the literature, the decrease in particles diameter leads to an increase in metal-support interaction and then a drop of the PdO reducibility $[17,30]$.

\section{Catalytic activity}

The methane conversion curves of the Pd-CeZrx catalysts are shown in Fig. 5. According to the conversion temperatures, $\mathrm{T}_{10}, \mathrm{~T}_{20}$ and $\mathrm{T}_{50}$ (respectively temperatures of 10 , 20 and $50 \%$ of methane conversion), the catalysts could be ordered as follows: Pd-CeZr5> Pd-CeZr10 >Pd-CeZr20> Pd-CeZr0 (Table 2). Consequently, these results show that, the addition of an appropriate loading of $\mathrm{Ce}$ and $\mathrm{Zr}$ to the $\mathrm{Pd} / \mathrm{MCM}-41$ catalyst can improve significantly its catalytic activity for methane combustion. Nevertheless, the further increase of the $\mathrm{Ce}$ and $\mathrm{Zr}$ contents on the Pd-CeZrx catalysts decreases dramatically the activity. It was established that interaction between $\mathrm{PdO}$ and $\mathrm{Ce}-\mathrm{Zr}$ oxides leads to better activity and better stability in methane combustion for $\mathrm{Pd} / \mathrm{Al}_{2} \mathrm{O}_{3}$ catalysts [20]. In fact, the addition of $\mathrm{Ce}-\mathrm{Zr}$ oxides stabilizes $\mathrm{PdO}_{\mathrm{x}}$ in a high oxidation state and enhances the re-oxidation properties of PdO under reaction conditions. The later hypothesis and the Pd dispersion improvement could be the reasons for the better activity of the Pd-CeZr5 catalyst compared to that of the PdCeZr0 sample.

Furthermore, it has been pointed out, that activity in methane combustion of the Pd based catalysts depends strongly on the PdO particle size and the Pd reducibility [31-33]. In our 
case, these two reasons could mainly explain the activity drop with the increase of $\mathrm{Ce}$ and $\mathrm{Zr}$ amounts from 5 to $20 \%$. In effect, according to the literature [34], an optimal particle size is needed in order to maximize a supported palladium catalyst. Small Pd particles (diameter less than $2 \mathrm{~nm}$ ) provide early ignition, medium size crystallites between 4 and $10 \mathrm{~nm}$ lead to an increase of the reaction rate while large particles (about $100 \mathrm{~nm}$ ) do not further improve the activity. Thus, the Pd-CeZr5 seems to have the adequate Pd particle size able to maximize the catalytic activity, since it shows a medium Pd particle sizes compared to those of the PdCeZrx catalysts. In addition, better reducibility is obtained on the Pd-CeZr5 due to the moderate interaction with the Ce-Zr oxides. Consequently, the variation of the $\mathrm{Ce}$ and $\mathrm{Zr}$ loadings seems to be a good tool to enhance based Pd catalysts. First, by the Pd dispersion improvement through the enhancement of the catalyst thermal stability. Then, by the particle size and the reducibility variation of PdO. Optimum values should be reached to maximize activity in methane combustion.

\section{Conclusion}

The following conclusions can be drawn from this work:

- The BET surface area and the pore volume of the Pd-CeZrx catalysts decreases significantly when $\mathrm{Ce}$ and $\mathrm{Zr}$ loadings increase. These results could be explained by the appearancy of new pores due to the destruction of the MCM-41 internal walls following the deposition of ceria and zirconia in the internal channels.

- Optimum addition of $\mathrm{Ce}$ and $\mathrm{Zr}$ contents to the $\mathrm{Pd} / \mathrm{MCM}-41$ catalyst enhances significantly the palladium dispersion, probably due the interaction improvement between $\mathrm{Pd}, \mathrm{Ce}$ and $\mathrm{Zr}$ oxides.

- $\mathrm{Ce}_{\mathrm{x}} \mathrm{Zr}_{1-\mathrm{x}} \mathrm{O}_{2}$ solid solutions could be formed on the Pd-CeZrx catalysts following substitution of $\mathrm{Ce}^{4+}$ ions by $\mathrm{Zr}^{4+}$ ions in the ceria lattice. 
- The excessive increase of $\mathrm{Ce}$ and $\mathrm{Zr}$ contents on the Pd-CeZrx solids lowers the catalyst reducibility due to the strengthening of the Pd interactions with $\mathrm{Ce}$ and $\mathrm{Zr}$ oxides.

- Optimum Ce and Zr loadings enhance the Pd-CeZrx activity in methane combustion, owing to the Pd dispersion increase, the Pd particle size optimization and the PdO reducibility improvement.

\section{Acknowledgement}

The authors are grateful to Mohamed SELMANE (Engineer at UPMC-Paris 6) for assistance in XRD and WAXS characterizations and Patrick LE GRIEL (engineering assistant at CNRS) for TEM images.

\section{References}

[1] S. Colussi, Alessandro Trovarelli, Cinzia Cristiani, Luca Lietti , Gianpiero Groppi, Catal. Today. 180 (2012) 124-130.

[2] Patrick Gélin, Michel Primet, Appl. Catal. B: Environ . 39 (2002) 1-37.

[3] Joelle Bassil , Abdulkader AlBarazi, Patrick Da Costa , Maya Boutros, Catal. Today. 176 (2011) 36-40.

[4] Juan A.C. Ruiz, Erica C. Oliveira, Marco A. Fraga, Heloise O. Pastore, Catal. Commun. 25 (2012) 1-6.

[5] Liu Wenge; Guo Deyong; Xu Xin, China. Petrol. Proc \& Petrochem. Techn. 14 (2012) 1-9.

[6] R. Gholami, Mina Alyani and Kevin J. Smith, Catal. 5 (2015) 561-594.

[7] Sara Colussi, Alessandro Trovarelli, Gianpiero Groppi, Jordi Llorca, Catal. Commun. 8 (2007) 1263-1266.

[8] Xing Fan1, Fan Wang1, Tianle Zhu1, Hong He, J. Environ. Sci. 24 (2012) 507-511.

[9] Juan A.C. Ruiz, Marco A. Fraga, Heloise O. Pastore, Appl. Catal. B: Environ. 76 (2007) 115-122.

[10] Sara Colussi, Fabrizio Arosio, Tania Montanari, Guido Busca, Gianpiero Groppi, Alessandro Trovarelli, Catal. Today. 155 (2010) 59-65.

[11] Sara Colussi, Alessandro Trovarelli, Erik Vesselli, Alessandro Baraldi, Giovanni Comelli, Gianpiero Groppi, Jordi Llorca, Appl. Catal. A: Gen. 390 (2010) 1-10.

[12]Yoshida H, Nakajima Y, Yazawa Y, Hattori. T, Appl. Catal. B: Environ. 71 (2007) 70-79.

[13] Schmal M, Souza M, Alegre V, Catal. Today. 118 (2006) 392-401. 
[14] S. Fessi, A.S. Mamede, A. Ghorbel, A. Rives, Catal. Commun. 27 (2012) 109-113.

[15] Liang Zhao, Hongqiang Qin, Ren'an Wu, Hanfa Zou, J. Chromatogr., A. 1228 (2012) 193-204.

[16] Zhou-jun Wang, Yuan Liu, Peng Shi, Chang-jun Liu, Yan Liu, Appl. Catal. B: Environ. 90 (2009) $570-577$.

[17] A.Gannouni, B.Albela, M.Saïd Zina, L. Bonneviot, Appl. Catal. A : Gen. 464-465 (2013) 116-127.

[18] M. Abdollahi-Alibeik, M. Pouriayevali, Catal. Commun. 22 (2012) 13-18.

[19] Li-Hui Ren, Hui-Li Zhang, An-Hui Lu, Yan Hao, Wen-Cui Li, Microporous Mesoporous Mater. 158 (2012) $7-12$.

[20] ZHOU Zhong-liang, JI Sheng-fu*, YIN Feng-xiang, LU Ze-xiang, LI Cheng-yue, J. Fuel. Chem. Techn. 35 (2007) 583-588.

[21] Jiubiao Hu, Changlin Yu, Yadong Bi, Longfu Wei, Jianchai Chen, Xirong Chen, Chin. J. Catal. 35 (2014) $8-20$.

[22] Xiaohong Wang, Guanzhong Lu, Yun Guo, Liangzhu Jiang, J. Mater. Sci. 44 (2009) 1294-1301.

[23] Xiaoning Guo, Guojuan Zhi, Xiaoyan Yan, Guoqiang Jin, Xiangyun Guo, Pascal Brault, Catal. Commun. 12 (2011) 870-874.

[24] E.M. Slavinskaya, R.V. Gulyaev, A.V. Zadesenets, O.A. Stonkus, V.I. Zaikovskii, Yu. V. Shubin, S.V. Korenev, A.I. Boronin, Appl. Catal. B : Environ. 166-167 (2015) 91-103.

[25] Patricia Benito, Manuel Gregori, Sara Andreoli, Giuseppe Fornasari, Francesca Ospitali, Stefano Millefanti, Maria Sol Avila, Teresita F. Garetto, Stefania Albonetti, Catal.Today. 246 (2015) 108-115.

[26] Ye Yuan, Zhimiao Wang, Hualiang An, Wei Xue, Yanji Wang, Chin. J. Catal. 36 (2015) 1142-1154.

[27] Fengxiang Yin, Shengfu Ji, Pingyi Wu, Fuzhen Zhao, Chengyue Li, J. Catal. 257(2008) 108-116.

[28] Hailong Zhang, Jianli Wang, Yanhua Zhang, Yi Jiao, Chengjun Ren, Maochu Gong, Yaoqiang Chen, Appl. Surf. Sci. 377 (2016) 48-55.

[29 Naoto Kamiuchi, Masaaki Haneda, Masakuni Ozawa, Catal.Today. 241(2015)100-106.

[30] M. Jablonska. Catal. Commun. 70 (2015) 66-71.

[31] L. M.T. Simpliicio, S.T. Brandao, E.A. Sales, L. Lietti, F. Bozon-Verduraz, Appl. Catal. B : Environ. 63 (2006) 9.

[32] O.M'Ramadj, D.Li, X.Wang, B. Zhang, G. Lu, Catal. Commun. 8 (2007) 880.

[33] C. Shi, L.Yang, J. Cai, Fuel. 86 (2007) 106.

[34] E. Pocoroba, L.J. Pettersson, J. Agrell, M. Boutonnet, K. Jansson, Top. Catal. 16-17 (2001) 407-412. 


\section{Table 1}

Textural properties of the $\mathrm{Pd}\left(\mathrm{Ce}_{\mathrm{x}} \mathrm{Zr}_{(1-\mathrm{x})} \mathrm{O}_{2}\right) / \mathrm{MCM}-41$ catalysts.

\begin{tabular}{|c|c|c|c|c|c|c|}
\hline \multirow[t]{2}{*}{ Catalysts } & \multirow[t]{2}{*}{$\mathrm{S}_{\mathrm{BET}}\left(\mathrm{m}^{2} / \mathrm{g}\right)$} & \multicolumn{3}{|c|}{ Dp (̊) } & \multirow[t]{2}{*}{$V p\left(\mathrm{~cm}^{3} / \mathrm{g}\right)$} & \multirow[t]{2}{*}{ D (\%) } \\
\hline & & $1^{\text {st } t y p e}$ & $2^{\text {nd }}$ type & $3^{\text {rd }}$ type & & \\
\hline Pd-CeZro & 860 & 31 & --- & --- & 0.95 & 14 \\
\hline Pd-CeZr5 & 888 & 27 & 43 & 203 & 0.51 & 28 \\
\hline Pd-CeZr10 & 521 & 24 & 38 & 233 & 0. & 35 \\
\hline Pd-CeZr20 & 330 & 24 & 36 & 228 & 0.41 & 37 \\
\hline
\end{tabular}

$\mathrm{S}_{\mathrm{BET}}$ BET surface area, Dp: average pore diameter, $\mathrm{Vp}$ : total pore volume and D: palladium dispersion.

Table 2

Temperature of iso-conversion of all catalysts.

\begin{tabular}{lllll}
\hline $\mathrm{T}\left({ }^{\circ} \mathrm{C}\right)$ & Pd-CeZr0 & Pd-CeZr5 & Pd-CeZr10 & Pd-CeZr20 \\
\hline T10 & 500 & 325 & 400 & 408 \\
T20 & --- & 333 & 428 & 440 \\
T50 & --- & 360 & 482 & --- \\
\hline
\end{tabular}


Fig. 1. (A) Adsorption-desorption isotherms of Pd-CeZr0, Pd-CeZr5, Pd-CeZr10 and Pd-CeZr20 catalysts and (B) Average pore distributions of Pd-CeZr0, Pd-CeZr5, Pd-CeZr10 and Pd-CeZr20 catalysts.

Fig. 2. (A) XRD patterns of the Pd-CeZrx catalysts and (B) XRD patterns of the $\mathrm{Pd} / \mathrm{CeO}_{2} / \mathrm{MCM}-41$ catalyst.

Fig. 3. TEM characterization of the Pd-CeZrx catalysts: (a) Pd-CeZr0 micrograph (b) EDXA of Pd-CeZr0 (c) Pd size distribution of the Pd-CeZr0 (d) Pd-CeZr5 micrograph (e) Pd size distribution of the Pd-CeZr5 (f) PdCeZr10 micrograph (g) HRTEM of the Pd-CeZr10 (h) Pd-CeZr20 micrograph (i) HRTEM of the Pd-CeZr20 and (j) EDXA of the Pd-CeZr20.

Fig. 4. TPR profiles of the Pd-CeZrx catalysts.

Fig. 5. Effect of cerium and zirconium loading on the activity of Pd-CeZrx catalysts. 

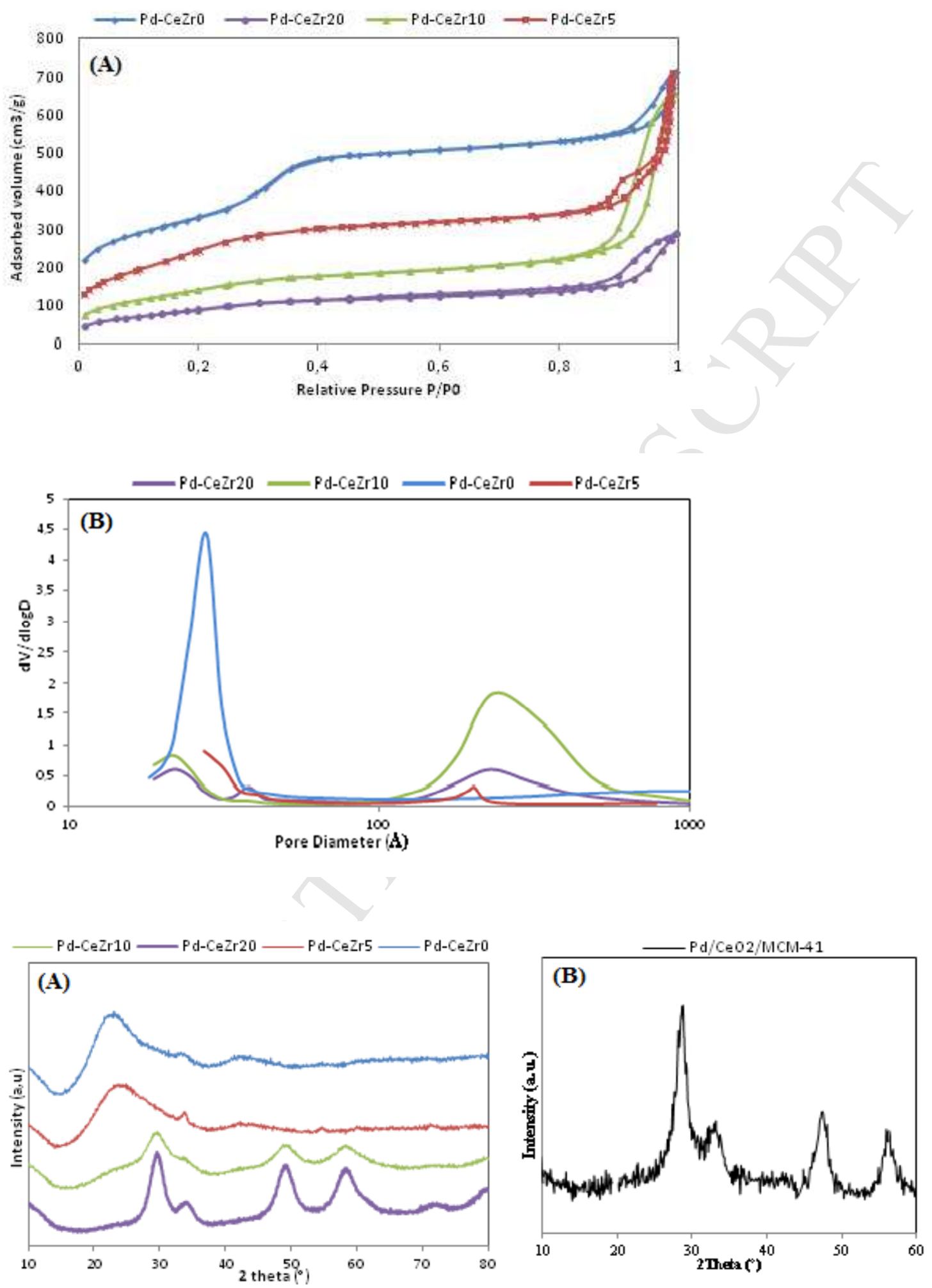

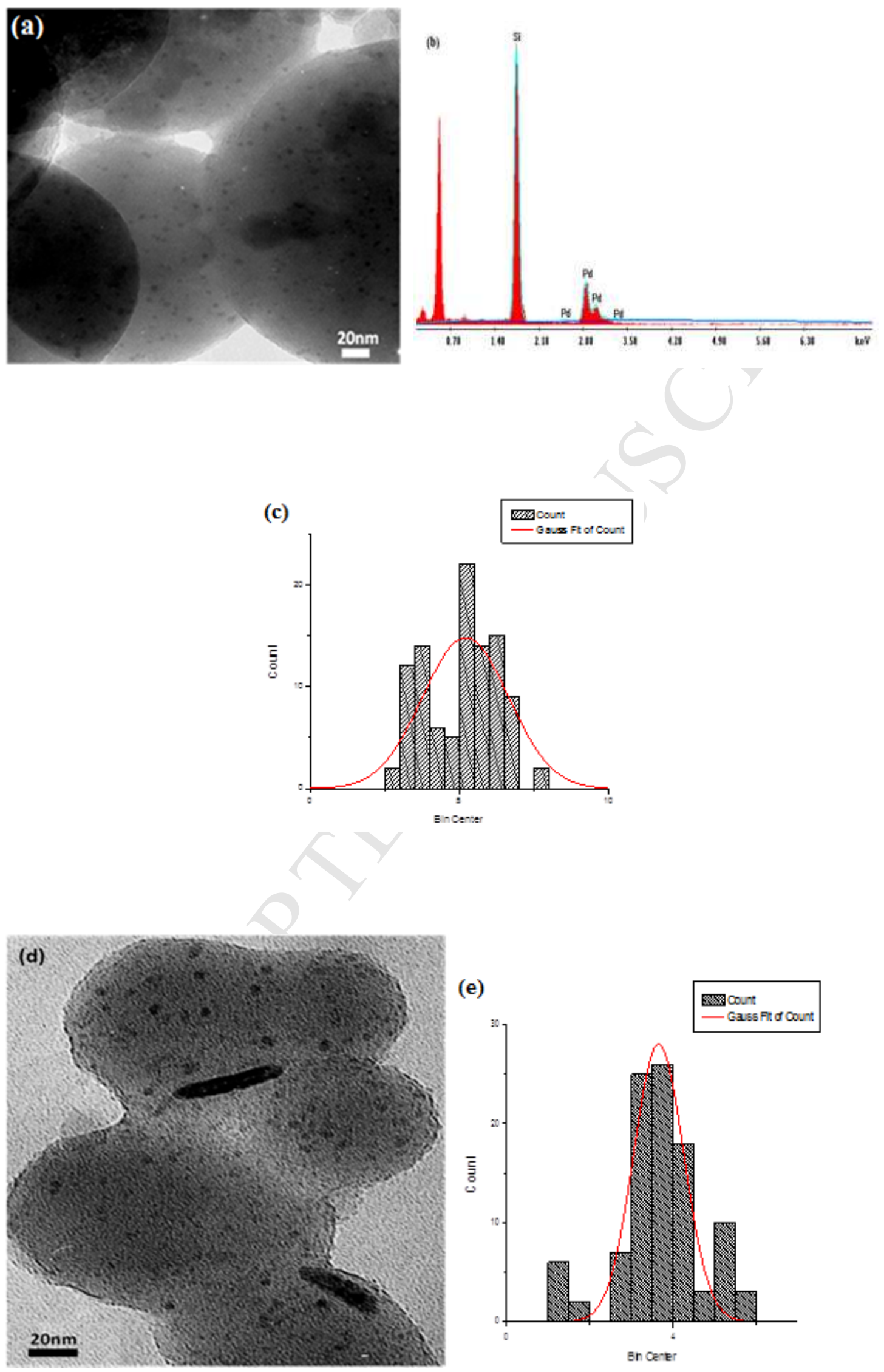

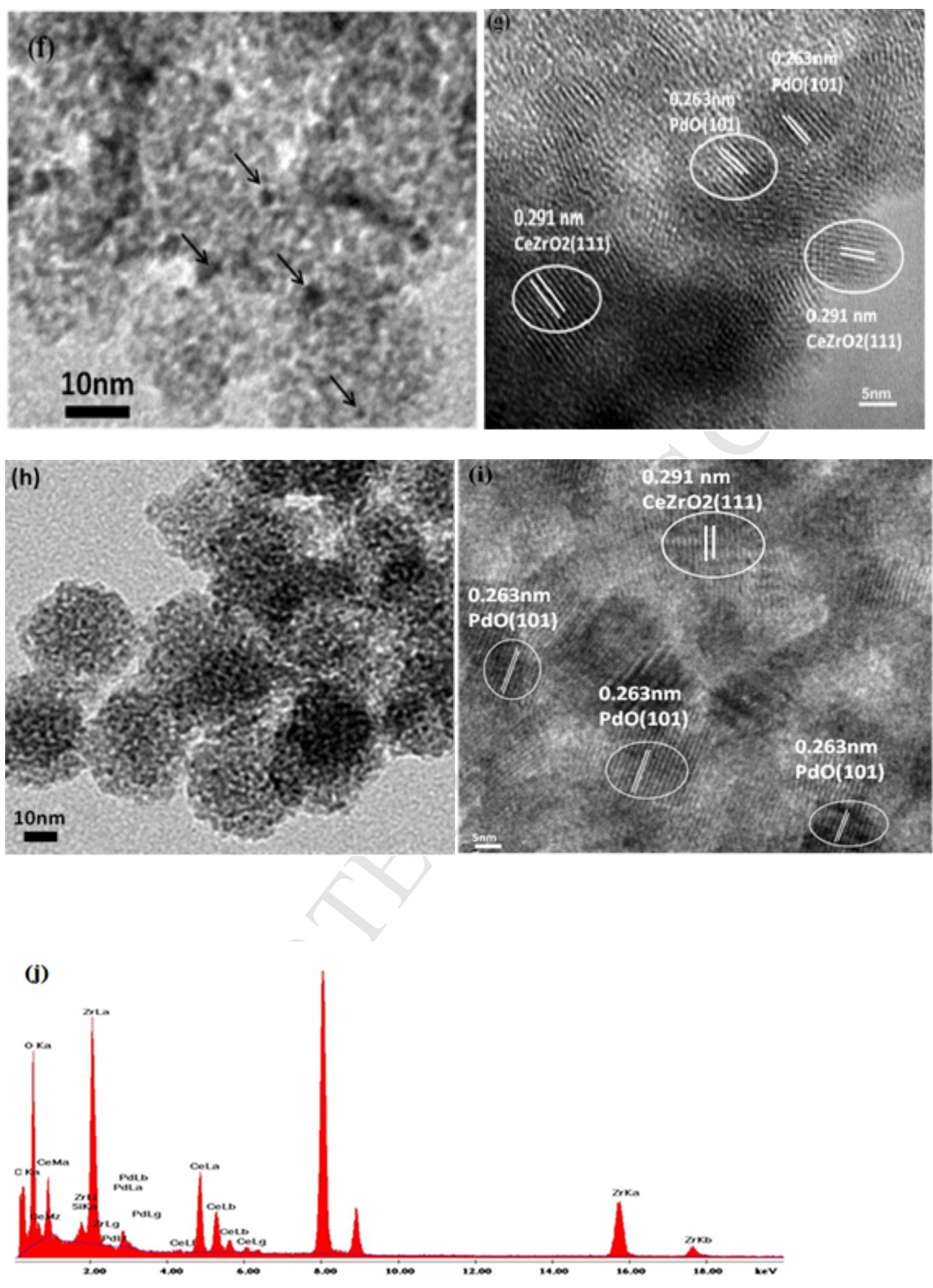

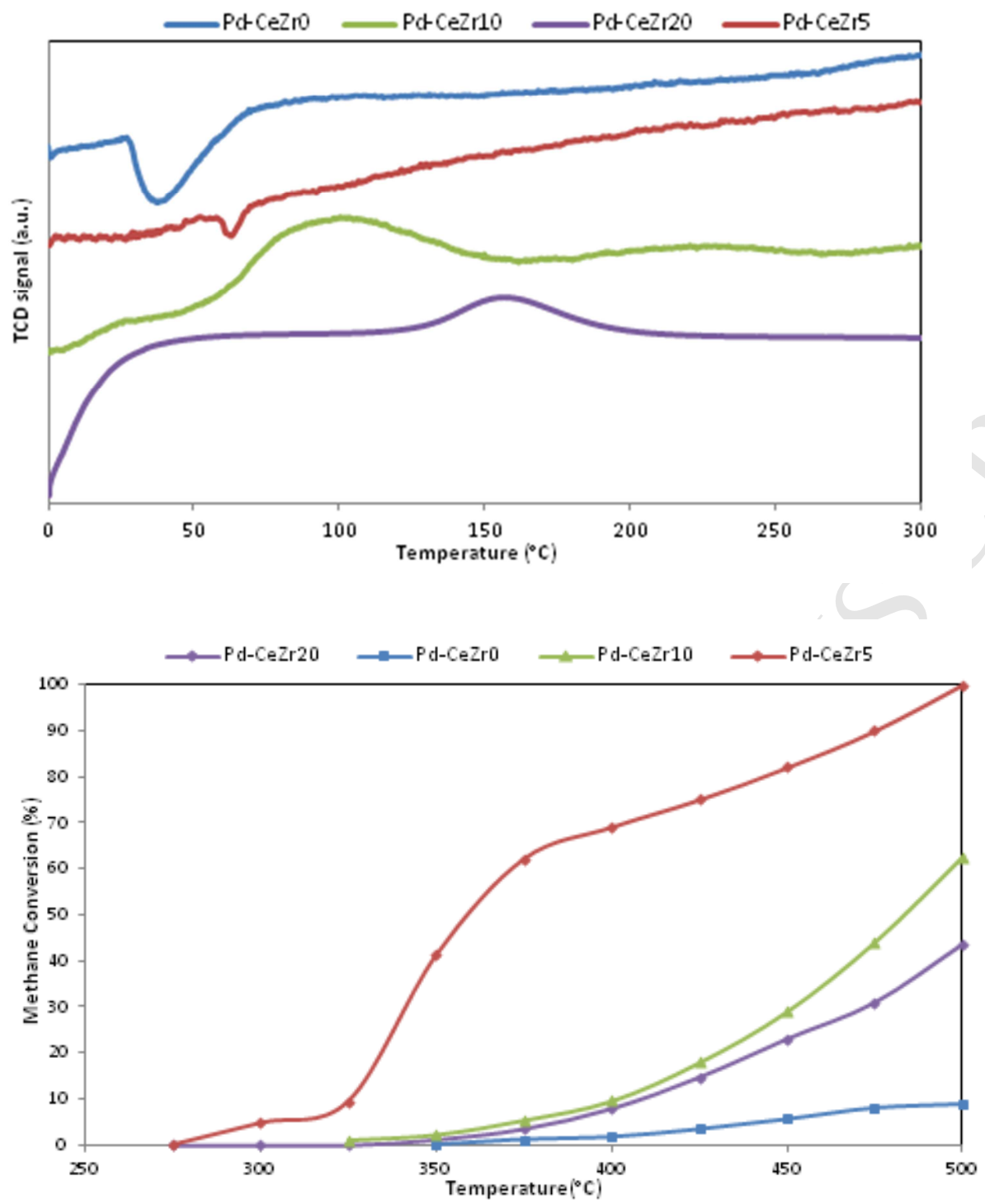


\section{Highlights}

- $\mathrm{Pd} / \mathrm{Ce}_{\mathrm{x}} \mathrm{Zr}_{(1-\mathrm{x})} \mathrm{O}_{2} @ \mathrm{MCM}-41$ catalysts were prepared by impregnation.

- The addition of Ce and $\mathrm{Zr}$ significantly enhances the catalytic activity for methane combustion

- The effect of Ce and $\mathrm{Zr}$ loading is studied.

- Catalytic activity is affected by the PdO reducibility and metallic particles size.

- Catalyst with low $\mathrm{Ce}$ and $\mathrm{Zr}$ content (5\%.wt) exhibits the best activity. 